\title{
Strategy Research on Construction of Local Universities in Regional Innovation System*
}

\author{
Yaomin Mei \\ Scientific Research Office \\ Zhuhai College of Jinlin University \\ Zhuhai, China
}

\begin{abstract}
The construction level of regional innovation system concerns the speed of implementing innovation strategy. As a part in construction of regional innovation system, local universities integrate resource superiority of disciplines, talents and experimental facilities and play a role in talent training, scientific research and serving the society. Consciousness of scientific and technological innovation is strengthened and leading organ of service and innovative management mechanism, innovation ability and level of science and technology service are improved, in order to serve the construction and development of regional innovation.
\end{abstract}

Keywords-local university; regional innovation system; integration

\section{INTRODUCTION}

The construction of innovation-oriented country must strengthen the construction of regional innovation system, in which universities are indispensable part. Universities center on science and technology development strategy and academic frontier and make full use of advantages in professional skills, talents, and platform and knowledge innovation capability, in order to promote regional innovation, scientific and technological development and achievement transformation. Therefore, strategy research on integration of local universities in construction of regional innovation system (take universities in Guangdong as an example), and sharing of "talents, capitals, information and technology" of local universities and areas promote regional innovation, scientific and technological development and achievement transformation of Guangdong province and discipline construction of local universities.

\section{CONNOTATION AND DEVELOPMENT OF REGIONAL INNOVATION SYSTEM}

\section{A. Basic Connotation of Regional Innovation System}

Regional innovation system (RIS) is the foundation and subsystem of national innovation system (NIS). The construction of innovation-oriented country must strengthen

*Fund project: 2015 Innovative Strong School Project of Education Department of Guangdong Province (key platform and major scientific research project)-Youth innovative talent project: 2015WQNCX171, Strategy Research on Construction of Local Universities in Regional Innovation System the construction of RIS, which improves regional innovation ability, regional competitiveness and NIS. RIS refers to the network system that gathers and integrates innovative elements to promote effective allocation of resources in certain region. "Innovative elements" include innovative subjects such as government, enterprise, university, scientific research institution, investment and financing institutions and professional intermediary service institution, and material and immaterial innovation resources required by innovation activities.

Functional goals and activity orientation of RIS make local universities have bright prospects in construction and development of RIS. Local universities have closer relationship with local areas, referring to the important carrier and platform of scientific and technological innovation, technology transformation and achievement transformation, the important base of talent training, knowledge creation, accumulation and transfer, and the important place to spread scientific spirit, scientific morality and cultural construction, shouldering glorious and arduous mission in the construction of RIS.

\section{B. Importance of Local Universities in the Construction of RIS}

In 2012, Ministry of Education introduced "Improvement Plan for Innovation Ability of Universities" ("2011 Plan" for short) and established "2011 Collaborative Innovation", in order to promote deep collaboration of universities, scientific research institutions, industry and enterprise, local government and foreign scientific research institutions, explore collaborative innovation model adaptive to different requirements and create environment and atmosphere of collaborative innovation. According to demands of "2011 Plan", collaborative innovation centers facing regional development lead the regional innovation development through promoting deep integration of universities and key enterprises or industrialization base in local pillar industry under the guidance of local government, in order to serve regional economic and social development. Universities are encouraged to construct core technology and key technology innovation team as well as platform of scientific and technological innovation, improve service system of it; establish innovation bases and promote transformation and industrialization of scientific and 
technological achievements; cultivate innovative talents and improve quality of talents.

In order to integrate in the construction of regional collaborative innovation system, local universities should strengthen discipline and specialty construction, improve the level of talent training and promote science and education innovation, management innovation, mechanism innovation and system innovation. Meanwhile, they have to promote the effective combination of knowledge innovation and technological innovation, the effective combination of technological innovation and market innovation, give full play to advantages of discipline and specialty, promote discipline development and promote profound interdisciplinary development.

\section{CURRENT SituATION OF LOCAL UNIVERSITIES} SERVICE REGIONAL INNOVATION-DRIVEN DEVELOPMENT

\section{A. Local Universities Have Low Consciousness of Serving Regional Innovation-Driven Development}

Serving innovation-driven development by local universities promotes regional economic development to meet interest and objective demand. Local universities pay attention to teaching task and lack large and advanced scientific research equipment. Incomplete scientific research system, restricted scientific research condition and outdated infrastructure of scientific research lead to insufficient scientific and technological innovation capacity and low level of science and technology service.

On Jun.15, 2017, the Ministry of Education publishes the list of formal universities in 2017. There are 2,914 universities in China, including 151 in Guangdong province. Sample survey is provided for 200 teachers in 20 local universities about the cooperation of industry, university and research. The research results show 40 percent of university teachers fail to deeply grasp regional humanity, history and economy and 60 percent of universities don't know regional enterprises need to make technological breakthrough. 50 enterprises in Guangdong province are investigated about the cooperation of industry, university and research. The result shows 80 percent of enterprises do not know the scientific research in universities and the research field of university teachers as well as achievements of scientific and technological innovation. Technical problems in enterprises cannot be solved and universities with technology cannot serve. Most cooperation of industry, university and research are unilateral cooperation between universities and enterprises, government and enterprises, government and universities. With small cooperation scale, it fails to fully integrate resources in universities, scientific research institutions and enterprises and goes against collaborative innovation and transformation of technological achievements. As an important part of RIS, compared with key universities, local universities have irreplaceable advantages, so attentions from local governments and the society should be paid to it. At the meantime, in regional innovation, local universities in Guangdong province need to exploit the advantages to the full.

\section{B. Coordinated Development of Local Universities and Regional Innovation Is An Arduous Task}

As an important part of Chinese higher education, local universities serve regional economic construction and social development, train application-oriented professionals and carry out scientific and technological innovation as well as research and development. With the popularization of higher education, local universities rise rapidly and promote higher education to meet social demands. Universities transform from transferring knowledge to developing knowledge, from "the tower of ivory" to "social service station". Local universities improve regional culture soft power and carry out talent training, scientific and technological innovation. ${ }^{1}$

Local universities are innovation organization most closely linked to local areas. In deep reform, innovationdriven development is distinctly important. Innovation is the life of organizers and determines the existence and development of organizers. Universities are teaching center and scientific research center. Teachers teach and do scientific research. Except for training local talents, local universities carry out scientific and technological innovation and knowledge innovation, in order to promote economic and social development. In developed areas, knowledge of local universities transforms into productivity more conveniently; in less developed areas, the chain of industry, university and research hasn't been established. The transformation of knowledge of local universities into productivity is difficult and requires improving ability of local universities through knowledge innovation, in order to better serve local economic and social development. ${ }^{2}$

\section{Integration of Local Universities in Regional Innovation System Is Required by Social Development}

The integration of local universities in the construction of regional collaborative innovation is carried out through integration of innovation and talent training, innovation and economic development, in order to realize connection between innovative talent training and market requirements, connection between innovative scientific and technological achievements and industrialization, connection between innovative management and mechanism of sustainable development.

With discipline and specialty advantage, talent advantage, knowledge innovation advantage, through improving capacity of independent innovation and contents of innovation system, local universities strengthen system construction and information platform construction and carry out talent training, scientific research, popularization and application of new technology as well as popularization of sciences, develop scientific and technological and social resources, meanwhile integrate in construction of regional

\footnotetext{
${ }^{1}$ Liu Keqin. Analysis on Regional Innovation-driven Development Served by Local Universities [J], Research in Education Development, Apr.10, 2014

${ }^{2}$ Guo Dongming. Implement Innovation-driven Strategy and Promote Collaborative Innovation of Science and Technology in University [J], Chinese Higher Education, October 18, 2014.
} 
innovation system. Interaction forms among scientific and technological innovation, regional economic development, local scientific and technological progress and cultural construction. Universities become important part of regional innovation system, base for training of high quality talents and scientific research, and important carrier and platform for regional innovation, technology and achievement transformation.

\section{INTEGRATION OF LOCAL UNIVERSITIES IN CONSTRUCTION OF REGIONAL INNOVATION SYSTEM HAS DEFICIENCIES.}

\section{A. Scientific Research and Innovation Orientation Is Unclear}

Although our country has good education tradition such as the proposition of "teach students in accordance with their aptitude", the traditional narrow discipline-oriented education concept deeply influences teachers in local universities. Local universities only pay attention to training talents and teaching instead of scientific research and train teachers in teaching reform and practice, prefer specialty construction to discipline construction. At the meantime, the unsound innovation assessment mechanism and the low proportion of scientific and technological innovation in performance evaluation on teachers make teachers attach importance to teaching instead of scientific research. Universities must have scientific orientation. They center on requirements of regional economic and social construction, reasonably provide discipline and make discipline construction coordinate with local industrial development, in order to provide necessary technical support for transformation and upgrading of regional enterprises. In scientific and technological innovation, universities must insist on correct application orientation. Interact with regional government, enterprises and public institutions, timely know about problems in regional economic and social development and closely integrate innovative products with it, in order to improve ability of scientific and technological innovation, increase the supply quantity of innovative products and enlarge the service area of local economic and social development.

\section{B. Implementation Deviation of Policies Related to Scientific and Technological Innovation in Universities}

Evaluation on scientific research for ranking of universities only values funds and quantity of scientific research. To pursue quantity of science and technology project approved, level and achievements, in organization and implementation, management layer of universities neglects the combination of teachers' scientific research and regional innovative development. Influenced by market economy environment and driven by interests, teachers regard funds of scientific and technological innovation as "quasi property" of their own and neglect application value and economic value of scientific and technological innovation. In professional title appraisal, attentions are paid to the quantity and quality of academic paper instead of scientific research and the transformation of scientific and technological achievements, leading to many "rubbish of scientific research". Assessment criterion, evaluation index and funds management of scientific and technological achievements lack standard policy guidance, leading to blundering ethos of science and technology and academic corruption, which influence the normal operation of scientific and technological innovation.

\section{Transformation Rate of Scientific and Technological Achievements Is Low}

At present, many excellent scientific payoffs cannot realize use value because the market mechanism is unsound, science and technology separates from economy, approval of scientific research project lacks market orientation, scientific researchers act blindly, scientific payoffs fail to enter enterprise; simple financing system and lack of funds make numerous excellent scientific payoffs fail in preparation. In 2015, investigation sent by Song He, an associate researcher in institute of science and technology policy and management science, CAS, indicates patents transferred and approved account for 2.03 percent in "living patent". Although there are many "dead patents" given up by universities, the proportion is lower. The proportion in CAS is a little higher, referring to 8.7 percent. ${ }^{3}$ In order to promote the transformation of scientific and technological achievements, on August 5, 2016, Ministry of Education and Ministry of Science and Technology introduced Opinions on Strengthening the Transformation of Scientific and Technological Achievements in Universities, requiring universities to establish transformation mechanism of scientific and technological achievements, improve income distribution policy about increasing knowledge values as well as ability in transformation of scientific and technological achievements.

\section{SUCCESSFUl CASES IN COOPERATION OF GOVERNMENT, SCHOOL AND ENTERPRISE}

\section{A. Successful Cases in Cooperation of Government, School and Enterprise at Abroad}

American government formulates sound plan related to cooperation of government, industry, school and research to strengthen cooperation and application and promote diversified participation, so science and technology innovation park in Silicon Valley produces. British government introduces financial subsidies to provide credit risk guarantee for enterprises in innovation. Meanwhile, it establishes public information platform, strengthens the cooperation between universities and enterprises, attaches equal importance to scientific research and education, pioneering "entrepreneur universities". Japan brings the cooperation of industry, school and research in basic state policy, realizes institutionalization of cooperation, establishes trans-departmental and cross-regional resource sharing network and establishes cooperation alliance of industry, school and research. South Korean government

\footnotetext{
${ }^{3}$ Zhao Ang. Is Transformation Rate of Scientific Research Achievement Really Very Low? [N], Workers’ Daily, Oct.1, 2016 (03).
} 
legislates on promoting cooperation of industry, school and research and provides financial preference, funding and service coordination and forms cooperation model of policy, industry, school and research, which promotes the rapid development of science and technology.

\section{B. Successful Cases in Cooperation of Government, School and Enterprise at Home}

Dominated by government, Zhongguancun in Beijing reforms cooperation of industry, school and research, formulates development plan and seizes industrialization development with scientific and technological innovation and achievement transformation. Government provides policy support and introduces enterprises and talents to promote integrative development of policy, industry, school and research, forming high-tech innovation park in about 30 years. Through cooperation of industry, school and research dominated by government, Yangtze River Delta Region attracts resources of science and technology as well as talents at home and abroad, integrates superior resources of enterprises and universities and realizes win-win cooperation of school, enterprise and government, forming a huge economic circle in several decades. In cooperation model of industry, school and research in Lujiazui, the government builds cooperation platform, promotes exchanges and cooperation of financing institutions, wellknown enterprises, brand specialties in famous universities at home and abroad and international renowned institutions of vocational qualification certificate. ${ }^{4}$

Zhejiang University establishes eight innovation and entrepreneurship platform or innovative research institutions related to public platform service, strategy consultancy plan, leading talent gathering, newly-rising enterprise incubation, high-tech transfer and cultivation of innovative talents to provide science and technology service and contribute to economic and social development, industry transformation and upgrading, transformation of high and new technology outcome as well as innovation and entrepreneurship development of scientific and technical personnel. South China University of Technology strives to make key technological breakthrough through connecting with professional town. It cooperates with leading enterprises to establish 40 innovation alliances of industry, school and research and 49 demonstration bases related to cooperation of industry, school and research. It forms "one college on town" or "one team one town" pattern with more than 100 professional towns in Guangdong province, to support industry transformation and upgrading roundly. Harbin Institute of Technology thoroughly solves bottleneck of investment decision-making of school-based industry through "one plus four" (namely fund plus technical team plus market plus professional management team), realizing enterprise operation according to market and economic law. Shanghai Jiaotong University creates powerful guarantee system for transformation of scientific and technological achievements that integrates financing, investment, project development, property right management, technology transfer, technical services, technology consulting and international technical cooperation. Northwestern Polytechnical University converts share model according to achievements, also called the pattern of "integration of research, experiment and industry", in order to carry out technical transformation by research teams, engineering centers and industrialized companies. Panyu government, together with regional university union, establishes incubation base of industry, school and research of health industry in Guangzhou Higher Education Mega Center, becoming domestic first-class science and technology entrepreneurship base that gathers industrial talents. Zhuhai College of Jilin University and regional government establish "advanced technology institute of middle and small-sized enterprises" that centers on advanced technology and latest industrial development such as biological medicine, new energy and materials, intelligent manufacturing, new generation of information communication and network security, in order to provide technical innovation like improvement of product quality, support of advanced technology, innovation and research and development of products and sharing of instrument and equipment as well as comprehensive science and technology service like talent training, scientific and technological consultancy, technology transfer, achievement transformation, business training and scientific and technological finance. It establishes "research and training center of aircraft engineering" through cooperation with Shaanxi Jinyu Aviation Technology Company Limited to implement projects such as "training in maintenance of civil aircraft", "academic education of aviation maintenance plus vocational training" and "undergraduate specialty construction of aviation maintenance".

\section{COUNTERMEASURES FOR LOCAL UNIVERSITIES TO INTEGRATE IN RIS CONSTRUCTION}

\section{A. Integrate in Innovation Actively, Clarify Responsibilities and Improve Systems}

Local universities must establish ideas on modern universities, clarify school-running orientation and adapt to new situation, trend and demands and carry out harmonious development with society. Attentions are paid to human resource development, sustainable development, cultural image related to intangible assets and democratic coordination. Service mechanism of scientific and technological innovation, evaluation system of scientific research must be improved. Local universities should strengthen the construction of characteristic discipline and specialty, clarify responsibilities of directors in it and center on demands of economic and social development, improve innovation ability of teachers, in order to improve the level of scientific and technological innovation, core competitiveness as well as accelerate the construction of application-oriented university.

\footnotetext{
4 Mei Yaomin. Research on Model and Mechanism of Regional Cooperation among Government, Industry, School and Research Based on Collaborative Innovation [J], Shang, 2015 (4): 73
} 


\section{B. Promote Organization, Establish Professional Leading} Agency and Grasp Top-Level Design

Establish innovation-driven service leading organ, strengthen policy and resource planning and establish mechanism of collaborative promotion, clarify division of labor and responsibilities and urge innovation-driven service. According to difficulties in transformation of scientific and technological achievements, strengthen top-level design and collaboration on and off campus related to policies, plan and reform measures of scientific research innovation. Mechanism in transformation of scientific and technological achievements is established. Policy support is provided for scientific and technological innovation to cultivate application-oriented achievements. Professional service posts are established to expand channels and promote transformation of scientific and technological achievements.

\section{Innovate in Management, Establish Incentive Mechanism and Release Innovation Potential}

Establish the valuation mechanism that self-evaluation of scientific research in universities combines with thirdparty evaluation of users, market and experts, to form an open and transparent evaluation environment. Teachers and scientific researchers are encouraged to carry out two-way communication with technicians in enterprises through improving entrepreneurship system of teachers, system of part-time job, entrepreneurship and returning to work of technicians. Technicians are encouraged to research and develop high and new technology, transform scientific and technological achievements, develop high and new technology industry. Transformation of scientific and technological achievements and industrialization management are standardized. Teachers and students are encouraged to innovate and transform scientific and technological achievements and release innovation potential. Distribution system about transformation of scientific and technological achievements are improved to guarantee benefits of universities and scientific researchers, stimulate their enthusiasm in innovation and entrepreneurship, in order to improve ability of regional social and economic service and promote regional innovation-driven development.

\section{CONCLUSION}

RIS system integrate elements of innovation such as regional government, enterprises, universities, scientific research institutions, investment and financing institutions and professional intermediary service institutions and carry out optimal configuration of resources, in order to promote coordinated development of regional science and technology, economy and society. Local universities should actively integrate in regional innovation-driven construction and promote regional innovative construction and integrate superior resources about discipline, talents and experimental facilities to promote regional innovation-driven development.

\section{REFERENCES}

[1] Yu Wensheng. Research on Development Status of Interaction between Local Universities and Regional Economic City and Countermeasures-Based on Investigation of Twelve Provincial Universities in Sichuan Province [J], Journal of Sichuan University of Arts and Science, May 10, 2016

[2] Liu Keqin. Analysis on Regional Innovation-driven Development Served by Local Universities [J], Research in Education Development, Apr.10, 2014

[3] Zhao Ang. Is Transformation Rate of Scientific Research Achievement Really Very Low? [N], Workers' Daily, Oct.1, 2016 (03)

[4] Guo Dongming. Implement Innovation-driven Strategy and Promote Collaborative Innovation of Science and Technology in University [J] Chinese Higher Education, October 18, 2014

[5] Mei Yaomin. Research on Model and Mechanism of Regional Cooperation among Government, Industry, School and Research Based on Collaborative Innovation [J], Shang, 2015 (4): 73

[6] Zeng Zhaohui, Wang Kuiwu, Hu Zeyou. Problems in Interactive Development between Local Universities and Regional Industry and Countermeasures [J], Agriculture and Technology, Mar.15, 2016

[7] Liu Nana. Research on Spatial-temporal Characteristics in Harmonious Development of Scientific and Technological Innovation of Universities and High Technology Industry and Driving Mechanism [J], Science of Science and Management of Science and Technology, October 10, 2015

[8] Chen Haihan. Research on Top-level Design of Scientific and Technological Innovation-driven System in Universities and Application Examples [J], Science and Technology Progress and Policy, Jul.7, 2015

[9] Yao Lihua. Give Full Play to University Function and Promote Innovation-driven Development [J], Seek Knowledge, Dec.5, 2013

[10] An Jianqiang. Discussion on Function of University in Innovation Drive [J], Scientific Advisory, Mar.5, 2013 